\title{
COMPARISON OF LONGEVITY, PACING, AND SENSING CHARACTERISTICS OF STEROID-ELUTING EPICARDIAL VERSUS CONVENTIONAL ENDOCARDIAL PACING LEADS IN CHILDREN
}

Gertie C. M. Beaufort-Krol, MD

Henk Mulder, BSN

Dick Nagelkerke, BSN

Tjalling W. Waterbolk, MD

Margreet Th. E. Bink-Boelkens, MD, PhD
Objective: Because of either cardiac anatomy or small size, pacing in children often occurs by means of epicardial leads. The disadvantage of epicardial leads is the shorter longevity of these leads compared with endocardial leads. During short-term follow-up, improved stimulation thresholds were found for the newer steroid-eluting epicardial leads. The longevity of these leads may be better than that of conventional epicardial leads. An improved longevity of epicardial leads may influence the choice to either epicardial or endocardial pacing in children. Methods: We studied the longevity and the pacing and sensing characteristics of 33 steroid-eluting epicardial pacing leads (group I, 15 atrial, 18 ventricular) implanted between November 1991 and October 1996 in 20 children with a mean age of $7.6 \pm 6.5$ years (mean \pm SD), and 29 endocardial pacing leads (group II, 15 atrial, 14 ventricular) implanted during the same period in 21 children with a mean age of $11.7 \pm 4.7$ years. Results: The mean follow-up in group I was $2.9 \pm 1.6$ years and in group II 3.1 \pm 1.7 years $(P=.61)$. The 2 -year survival of the leads in group I was $91 \% \pm 5 \%$ and in group II $86 \% \pm 7 \%(P=.97)$. Lead failure occurred in both groups in 4 leads $(P=.85)$. Chronic stimulation and sensing thresholds were similar. Conclusions: Steroid-eluting epicardial leads have the same longevity as the conventional endocardial leads. Pacing and sensing thresholds were similar and did not change during follow-up. Therefore steroid-eluting epicardial pacing leads are a good alternative for endocardial leads in small children and in children with congenital heart disease. (J Thorac Cardiovasc Surg 1999;117:523-8)
$\mathrm{B}^{\mathrm{c}}$ cause of either cardiac anatomy or small size, pacing in children often occurs by means of epicardial leads. The disadvantage of epicardial leads is the shorter longevity of these leads compared with endocardial leads, because of an increase in stimulation threshold resulting in an exit block. ${ }^{1-4}$ The 2-year survival of conventional epicardial leads in our department was $71 \% \pm$ $10 \%$, compared with $93 \% \pm 7 \%$ for endocardial leads. ${ }^{2}$ As an alternative for epicardial leads, endocardial leads may be used. However, because of the small size of the

From the Beatrix Children's Hospital, Division of Pediatric Cardiology, and Thoracic Center, University of Groningen, Groningen, The Netherlands.

Received for publication July 7, 1998; revisions requested Sept 17 , 1998; revisions received Oct 9, 1998; accepted for publication Oct 20, 1998.

Address for reprints: Gertie C. M. Beaufort-Krol, MD, Beatrix Children's Hospital, Division of Pediatric Cardiology, Hanzeplein 1, PO Box 30001, 9700 RB Groningen, The Netherlands.

Copyright (C) 1999 by Mosby, Inc.

$0022-5223 / 99 \$ 8.00+0 \quad \mathbf{1 2 / 1 / 9 5 2 9 2}$ veins in children, it may be difficult to place 2 leads, which are often required for physiologic pacing. Recently steroid-eluting epicardial leads have become available. Because improved stimulation thresholds were described during short-term follow-up, ${ }^{5-12}$ the longevity of these leads may be better. An improved longevity of epicardial leads may influence the choice for either epicardial or endocardial pacing in children. To our knowledge, there is no study that compares the results of the steroid-eluting epicardial leads with those of conventional endocardial leads. Therefore we compared, in children, the longevity and the pacing and sensing characteristics of the steroid-eluting epicardial lead with those of the conventional endocardial lead implanted during the same time period.

\section{Methods}

Patients. Between November 1991 and October 1996, 41 children underwent implantation of 62 pacing leads consisting of either steroid-eluting epicardial pacing leads (group I) or conventional endocardial pacing leads (group II). Informed 
Table I. Patient and pacing characteristics of steroideluting epicardial (group I) and endocardial leads (group II)

\begin{tabular}{llll}
\hline & $\begin{array}{c}\text { Steroid-eluting } \\
\text { epicardial } \\
\text { leads: } \\
\text { group I } \\
(n=33)\end{array}$ & $\begin{array}{c}\text { Conventional } \\
\text { endocardial } \\
\text { leads: } \\
\text { group II } \\
(n=29)\end{array}$ & P value \\
\hline No. of patients & 20 & 21 & \\
Age at implantation & $7.6 \pm 6.5$ & $11.7 \pm 4.7$ & .02 \\
$\quad$ y) & $9 / 11$ & $11 / 10$ & .64 \\
M/F & $3 / 17$ & $10 / 11$ & .01 \\
CHD (no/yes) & & & \\
Indications & 5 & 6 & .80 \\
Congenital AV block & 8 & 3 & .06 \\
Surgical AV block & 8 & .92 \\
Sick sinus syndrome & 6 & 6 & .01 \\
Long QT syndrome & 0 & 60 & .62 \\
$\quad$ Other & 1 & 0 & \\
Lead atrial/ventricular & $15 / 18$ & $15 / 14$ & .61 \\
pocket & & $3 / 18$ & .85 \\
Abdominal/subpectoral & $20 / 0$ & $3.1 \pm 1.7$ & \\
Follow-up (y) & $2.9 \pm 1.6$ & 4 & \\
Failure (n) & 4 &
\end{tabular}

$C H D$, congenital heart disease; $A V$, atrioventricular.

consent was obtained from each child and/or parents. Indications for epicardial pacing leads were the presence of congenital heart disease, simultaneous cardiac operation, and/or weight less than $20 \mathrm{~kg}$. Indications for endocardial pacing leads were weight more than $20 \mathrm{~kg}$ and either normal anatomy or anatomy suitable for endocardial pacing. Group I consisted of 20 patients with 33 steroid-eluting epicardial pacing leads; group II consisted of 21 patients with 29 conventional endocardial pacing leads. Seventeen children in group I and 10 children in group II had undergone, previously $(\mathrm{n}=11$ children $)$ or simultaneously ( $\mathrm{n}=6$ children $)$, palliative ( $\mathrm{n}=2$ children) or corrective ( $\mathrm{n}=15$ children) operations for the congenital heart disease. Patient characteristics are shown in Table I. There was no difference in patient characteristics between the 2 groups, except for the age at implantation and the presence of congenital heart disease. Long QT syndrome, as indication for pacing, occurred more often in group II (Table I). Once each year, a check-up at the pediatric outpatient clinic (including a 24-hour ambulatory monitoring) was performed.

Pacemaker leads. Group I consisted of 15 atrial leads (12 Medtronic 10366, 2 Medtronic SP 2139, 1 Medtronic 2823; Medtronic, Inc, Minneapolis, Minn) inserted via sternotomy ( $\mathrm{n}=7$ leads), lateral thoracotomy ( $\mathrm{n}=7$ leads), or subxiphoid approach $(\mathrm{n}=1$ lead) and 18 ventricular leads (14 Medtronic 10366, 2 Medtronic SP 2139, 2 Medtronic 2823 [Medtronic, Inc]) inserted via sternotomy ( $\mathrm{n}=6$ leads), lateral thoracotomy ( $\mathrm{n}=6$ leads), or subxiphoid approach ( $\mathrm{n}=6$ leads). Group II consisted of 15 atrial leads (6 Intermedics 438-01, 4 Intermedics 438-05, 1 Intermedics 432-02, 1 Intermedics
435-02, 1 Intermedics 438-10; Intermedics, Inc, Angleton, Tex; 2 Siemens Elema 1028T; Pacesetter, Inc, Sylmar, Calif) inserted through the subclavian or cephalic vein $(n=14$ leads) or transmurally ( $\mathrm{n}=1$ lead) and 14 ventricular leads ( 4 Intermedics 430-02, 3 Intermedics 430-10, 2 Intermedics 431-04, 2 Intermedics 425-13, 2 Intermedics 438-05, 1 Intermedics 403-07; Intermedics, Inc) inserted through the subclavian or cephalic vein ( $\mathrm{n}=12$ leads) or transmurally ( $\mathrm{n}$ $=2$ leads). Except for 4 unipolar leads in group I and 5 leads in group II, all the leads were bipolar. In group II, 13 leads had an active fixation (screw in) and 16 had a passive fixation (tined).

Surgical technique. The epicardial leads (mostly bipolar) were inserted by standard surgical techniques either through a lateral thoracotomy, a midline sternotomy, or a subxiphoid approach, whatever seemed appropriate considering heart morphologic condition and/or previous cardiac operation. The bipolar steroid-eluting epicardial leads consist of 2 patches with electrodes (platinized, porous, cathode $6.0 \mathrm{~mm}^{2}$; anode $14.0 \mathrm{~mm}^{2}$ ). Both electrode ends were fixed on the epicardium with two 6-0 Prolene sutures (Ethicon, Inc, Somerville, NJ) for each electrode. Care was taken to fix the electrode ends in such a way that they could not dislocate. The smaller electrode (cathode) was fixed closest to the sinus node (atrial position) or on the best available site on the ventricle, often on the diaphragmatic site of the right ventricular surface, which is almost always free of epicardial fibrosis after previous cardiac operation. The other electrode (anode) was fixed at least $1 \mathrm{~cm}$ from the other electrode, which was sometimes challenging in small babies. The surplus of length is dealt with by making wide loops of the electrode within the pericardium and within the pacemaker pocket. In small babies, it might be necessary to open both rectal sheaths to create a large enough pacemaker pocket. The pacemaker box and redundant electrode were placed behind the rectal muscle. Endocardial leads were inserted through the cephalic (by direct access) or subclavian (by puncture and with a removable sheath) vein. Occasionally an endocardial lead was introduced transmurally by passing the electrode through the wall of the appropriate cardiac chamber, fixing it with a purse-string suture.

Lead function analysis. The acute measurements were performed with a Pacing System Analyzer (PSA 5311; Medtronic, Inc). Stimulation voltage thresholds were measured with a pulse width of $0.5 \mathrm{~ms}$. Sensing thresholds were measured by filtered $\mathrm{P}$ and $\mathrm{R}$ wave amplitudes. Slew rates and impedances were measured. During follow-up (1 day, 6 weeks, and 3 months after implantation and every 6 months thereafter) the minimum energy threshold in microjoules (1 microjoule $=(\text { volts })^{2} \cdot$ milliseconds $\left.\cdot 1000 / \Omega\right)$ to standardize the measurements of stimulation thresholds was used. ${ }^{5} \mathrm{P}$ and $\mathrm{R}$ wave amplitudes and impedances were performed at each visit. $\mathrm{P}$ wave amplitudes of more than $3.5 \mathrm{mV}$ were noted as $4 \mathrm{mV}$, and $\mathrm{R}$ wave amplitudes of more than $7 \mathrm{mV}$ were noted as $8 \mathrm{mV}$.

Statistical analysis. Data are expressed as mean \pm SD. Log rank test and Kaplan-Meier product-limit estimates of sur- 


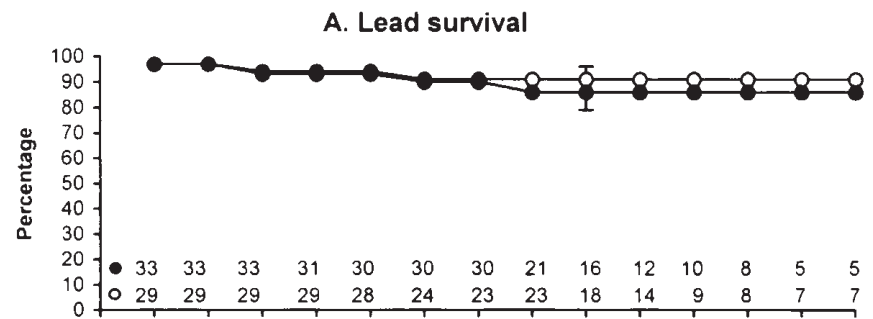

B. Stimulation thresholds

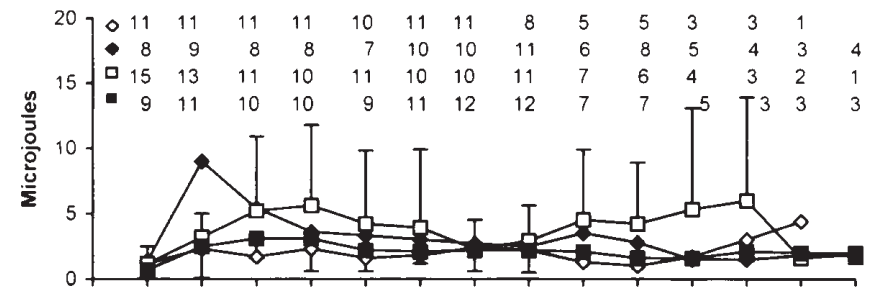

C. Sensing thresholds
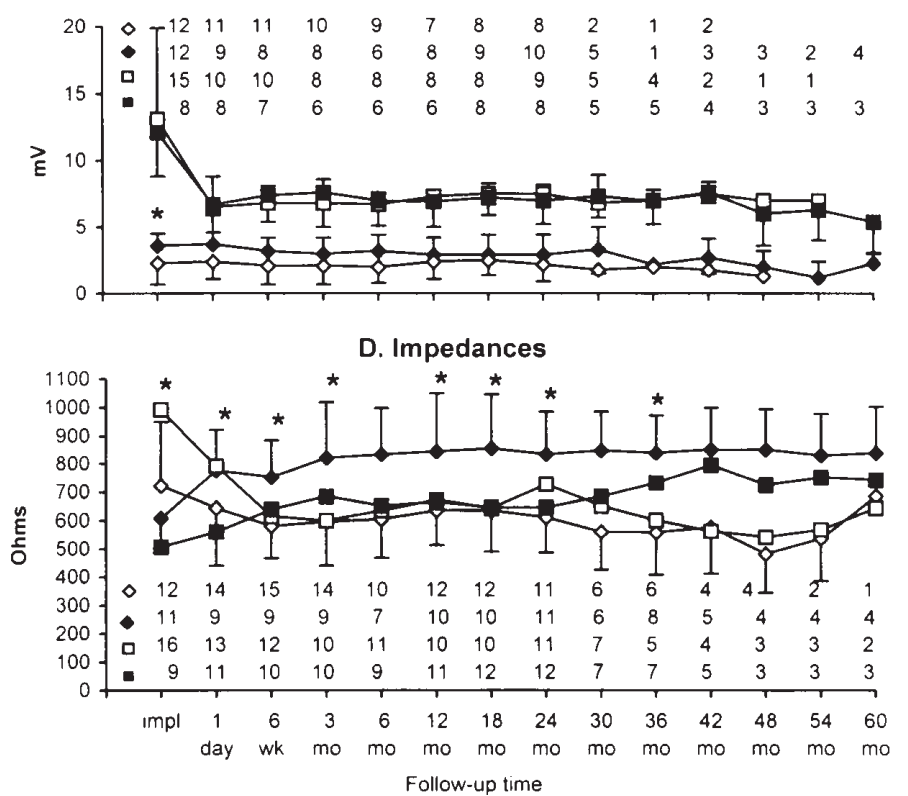

Fig 1. Lead survival (A), stimulation thresholds $(\mathbf{B})$, sensing thresholds $(\mathbf{C})$, and impedances $(\mathbf{D})$ of steroid-eluting epicardial versus conventional endocardial pacing leads. The numbers in the panels indicate the number of observations at that point. For graphic reasons, $\mathbf{S D}$ is in $\mathbf{B}$ only shown for ventricular leads, and in $\mathbf{D}$ only for atrial leads. ${ }^{*} P<.05$, group I vs group II. Open circle, steroid-eluting epicardial leads; closed circle, endocardial leads; open diamond, atrial steroid-eluting epicardial leads; closed diamond, atrial endocardial leads; open square, ventricular steroid-eluting epicardial leads; closed square, ventricular endocardial leads.

vival curves were used for longevity of leads. Patient deaths were considered as lost to follow-up. To compare patient characteristics, we used the Student $t$ test or a $\chi^{2}$ test. To compare pacing and sensing characteristics during the follow-up, we used repeated measurements of analysis of variance, followed by the Student $t$ test for paired values. The analysis was performed with a statistical computer program (NCSS, Kaysville, Utah).

\section{Results}

Patients. Three patients (1 patient in group I and 2 patients in group II) had a large increase in stimulation threshold in the early postoperative period, which was treated with prednisone orally ( $2 \mathrm{mg} / \mathrm{kg}$ per day). In all 3 patients, the stimulation thresholds decreased within a few weeks and remained low. In group I, 1 child with 
a congenital complete atrioventricular block and severe cardiomyopathy died of ventricular fibrillation 2.5 years after implantation of the epicardial lead. In group II, 1 child with complex congenital heart disease died of fungal endocarditis with multiorgan failure 1 year after implantation of the transvenous lead.

Lead survival. The 2-year survival of the leads was similar between the 2 groups (group I, 91\% $\pm 5 \%$; group II, $86 \% \pm 7 \% ; P=.97$; Fig $1, A$ ). The mean follow-up was $2.9 \pm 1.6$ years in group I and $3.1 \pm 1.7$ years in group II $(P=.61)$. The number of lead failures was 4 in both groups $(P=.85)$. All failures occurred in bipolar leads. In group I, 1 lead had to be removed because of a pocket infection, and the other 3 leads had to be removed because of an exit block ( 1 week, 0.5 year, and 5.75 years after implantation). The exit block 1 week after implantation occurred in a child in whom a previous epicardial screw lead had left numerous scars in the epicardium. In group II, 1 lead had to be removed because of a pocket infection; 2 leads had to be removed because of an exit block ( 1 and 1.5 years after implantation), and 1 lead had to be removed because of a broken connection between the lead and the header of the pacemaker. When we exclude the 2 pocket infections from the data of the survival analysis, the 2-year survival remains similar between the 2 groups $(93 \% \pm 5 \%$ vs $87 \% \pm 7 \% ; P=.94)$. The pacing and sensing characteristics of the mentioned 2 leads in the patients with a pocket infection were not incorporated in the long-term measurements.

\section{Pacing characteristics}

Acute. The acute stimulation voltage thresholds (1.0 \pm $0.4 \mathrm{~V}$ in group I vs $0.8 \pm 0.3 \mathrm{~V}$ in group II; $P=.40)$, the minimum energy thresholds $(1.2 \pm 1.4 \mu \mathrm{J}$ vs $1.3 \pm 1.3$ $\mu \mathrm{J} ; P=.82)$, and the slew rates $(1.2 \pm 1.7 \mathrm{~V} / \mathrm{s}$ vs $0.8 \pm$ $0.4 \mathrm{~V} / \mathrm{s} ; P=.40$ ) of the atrial leads were similar in the two groups.

The acute stimulation voltage thresholds were higher in group I than in group II $(1.2 \pm 0.5 \mathrm{~V}$ vs $0.7 \pm 0.2 \mathrm{~V} ; P=$ $.02)$. Both the minimum energy thresholds of the ventricular leads $(1.2 \pm 1.3 \mu \mathrm{J}$ vs $0.7 \pm 0.4 \mu \mathrm{J} ; P=.17)$ and the slew rates $(1.8 \pm 1.1 \mathrm{~V} / \mathrm{s}$ vs $1.2 \pm 0.6 \mathrm{~V} / \mathrm{s} ; P=.12)$ of the ventricular leads were similar.

Chronic. There was an increase in stimulation thresholds of all leads in both groups in the early postoperative period. This was less for the steroid-eluting epicardial leads. Later during follow-up, there was no difference in stimulation thresholds between the two groups (Fig 1,B). During follow-up the stimulation thresholds did not increase in either group.

\section{Sensing characteristics}

Acute. The sensed $\mathrm{P}$ wave amplitudes were lower in group I than in group II $(2.3 \pm 1.6 \mathrm{mV}$ vs $3.6 \pm 0.9 \mathrm{mV}$;
$P=.02)$. The sensed $\mathrm{R}$ wave amplitudes were similar in the two groups $(13.1 \pm 7.8 \mathrm{mV}$ vs $12.1 \pm 3.3 \mathrm{mV} ; P$ $=.44)$.

Chronic. During follow-up there was no statistically significant difference in sensing thresholds of $\mathrm{P}$ and $\mathrm{R}$ waves between the 2 groups (Fig 1,C). After an initial artificial decrease, caused by the difference in the technique of measurement, the sensing threshold of the $\mathrm{R}$ wave remained similar in the two groups. All sensing problems, detected during 24-hour ambulatory monitoring in both groups, could be solved by changing the pacemaker sensitivity settings.

\section{Impedances}

Acute. Atrial impedances tended to be higher in group I $(723 \pm 227 \Omega$ vs $609 \pm 122 \Omega ; P=.07)$. Ventricular impedances were higher in group I (993 \pm $333 \Omega$ vs $507 \pm 157 \Omega ; P=.0004)$.

Chronic. Atrial impedances were lower in group I than in group II (Fig 1, D). There was no difference in ventricular impedances between the two groups during follow-up. All measured values of impedances were within the normal range.

\section{Discussion}

Steroid-eluting epicardial versus conventional endocardial leads. The results of this study show that the longevity of steroid-eluting epicardial pacing leads is similar to that of conventional endocardial pacing leads implanted during the same time period. The 2year survival of the steroid-eluting epicardial leads was better than the previously described 2-year survival of non-steroid-eluting epicardial leads in our department, which was $71 \% \pm 10 \% .^{2}$ Fortunately, we did not encounter that high incidence of exit blocks in our steroid-eluting epicardial leads as described by Beder and associates, ${ }^{13}$ who found an exit block in 3 of 11 patients. Cutler and colleagues ${ }^{14}$ found no exit block in 22 patients with steroid-eluting epicardial pacing electrodes, which were studied for up to 6 years. Because of the similar longevity and pacing and sensing characteristics between the 2 leads found in our patients, steroid-eluting epicardial leads may be a good alternative to endocardial leads.

Choice of pacing lead at implantation. Although for some children the choice of pacing leads is limited to epicardial leads (eg, after an operation such as a total cavopulmonary connection), for most children the choice of pacing leads can be in favor of either an epicardial or an endocardial lead. The choice of pacing lead was based primarily on the age of the child; young children received an epicardial lead, whereas older children received an endocardial lead. However, because the results of endocardial leads were better than those of 
non-steroid-eluting epicardial leads, ${ }^{1,2}$ there is a tendency to implant endocardial leads at a younger age. The results of our study show that steroid-eluting epicardial leads are as good as endocardial leads. Therefore the choice of the pacing lead will be determined mainly by the advantages and disadvantages of either implantation technique. Advantages of epicardial leads are the applicability in every child, the possibility to combine the implantation of the leads with a corrective or palliative operation, fewer problems with the growth of the child, and the absence of the need for anticoagulation in children with a right-to-left shunt. Disadvantages of epicardial leads are the more extensive surgical procedure and the damage to the epicardial wall, which may result in difficulty in finding epicardium without scars for implantation of another epicardial lead. An advantage of endocardial leads is the less extensive surgical procedure. Disadvantages of endocardial leads are the small size of the veins, the risk of venous obstruction, ${ }^{15}$ and the need for the accommodation of the lead to the child's growth.

Choice of pacing lead for the future. The advantages and disadvantages relate to the period of implantation of the leads. Although the results of transvenous endocardial pacing in young infants are encouraging, ${ }^{16,17}$ we also have to consider the consequences of the choice of the lead for the future. Particularly in young children who will need pacing for the whole of their lives, it can be expected that multiple subsequent leads will be required. Although the methods for extraction of pacing leads are improving, ${ }^{18}$ serious complications of the extraction procedure have been described, and sometimes a heart operation is required. ${ }^{19}$ When lead extraction fails, a situation with multiple leads in 1 vein in a child, who was in need of pacing from birth, may occur. Multiple leads in the same vein may result in several complications, such as an increased risk of venous obstruction ${ }^{15}$ and an inability of the surgeon to insert new additional leads, when necessary. Because our study shows that steroid-eluting epicardial leads are a good alternative to endocardial leads, it would perhaps be reasonable to pace children epicardially as long as possible and save their veins for a period later during lifetime.

Study limitations. A limitation of this study is the relatively short follow-up time. However, this also applies for the studies with endocardial leads in young infants. ${ }^{16,17}$ A disadvantage of the steroid-eluting epicardial leads in this study was the lower impedances of the atrial leads during follow-up, which means that more energy may be required for pacing, which could limit the longevity of the pacemaker unit. The follow-up time in our study was too short to evaluate the longevi- ty of the pacemaker unit. Perhaps new designs of the steroid-eluting epicardial leads with smaller surfaces of the electrodes may improve impedance values in children, because animal studies have shown that the impedances of these leads remained high during a follow-up of 6 months. ${ }^{8}$ Further longitudinal studies are needed to compare steroid-eluting epicardial leads with endocardial leads in young infants to answer the question of which pacing lead implanted in infancy will have a reduced complication rate during adulthood. In addition, it can be worthwhile to investigate whether the use of steroid-eluting endocardial pacing leads in children may improve the results of endocardial pacing further.

\section{Conclusions}

We conclude that the longevity of steroid-eluting epicardial pacing leads in children is similar to that of the conventional endocardial pacing leads. Pacing and sensing thresholds were similar and did not change during follow-up. We therefore prefer the use of steroid-eluting epicardial leads to endocardial pacing leads in infants and small children because they need to be paced for the whole of their lives.

We thank A. H. van Kampen-Panjer for assistance in collecting the technical data of the pacemaker follow-up measurements and J. R. G. Kuipers (Head of the Division of Pediatric Cardiology) for his assistance in preparing the manuscript.

\section{REFERENCES}

1. Henglein D, Gillette PC, Shannon C, Burns G. Long-term followup of pulse width threshold of transvenous and myo-epicardial leads. PACE 1984;7:203-14.

2. Kerstjens-Frederikse MWS, Bink-Boelkens MThE, Jongste MJL de, Homan van der Heide JN. Permanent cardiac pacing in children: morbidity and efficacy of follow-up. Int $\mathrm{J}$ Cardiol 1991;33:207-14

3. Nordlander R, Pehrsson SK, Böök K, Zetterqvist P, Fahlén-Vepsä I. Clinical experience of pacemaker treatment in children. Scand J Thorac Cardiovasc Surg 1992;26:69-72.

4. Williams WG, Hesslein PS, Kormos R. Exit block in children with pacemakers. Clin Prog Electrophysiol Pacing 1986;4:478-89.

5. Hamilton R, Gow R, Bahoric B, Griffiths J, Freedom R, Williams W. Steroid-eluting epicardial leads in pediatrics: improved epicardial thresholds in the first year. PACE 1991;14:2066-72.

6. Johns JA, Fish FA, Burger JD, Hammon JW Jr. Steroid-eluting epicardial pacing leads in pediatric patients: encouraging early results. J Am Coll Cardiol 1992;20:395-401.

7. Karpawich PP, Hakimi M, Arciniegas E, Cavitt DL. Improved chronic epicardial pacing in children: steroid contribution to porous platinized electrodes. PACE 1992;15:1151-7.

8. Karpawich PP, Stokes KB, Proctor K, Schallhorn R, McVenes R, Factkor M. Improved epimyocardial pacing: initial experience with a new bipolar, steroid-eluting, high impedance lead design. PACE 1994;17:2032-7.

9. Kugler JD, Fetter J, Fleming W, Kilzer K, Stoehr D, Felix G, et 
al. A new steroid-eluting epicardial lead: experience with atrial and ventricular implantation in the immature swine. PACE 1990; 13:976-81.

10. Stokes KB. Preliminary studies on a new steroid eluting epicardial electrode. PACE 1988;11:1797-803.

11. Klein HH, Steinberger J, Knake W. Stimulation characteristics of a steroid-eluting electrode compared with three conventional electrodes. PACE 1990;13:134-7.

12. Crossley GH, Brinker JA, Reynolds D, Spencer W, Johnson WB, Hurd $\mathrm{H}$, et al. Steroid elution improves the stimulation threshold in an active-fixation atrial permanent pacing lead: a randomized, controlled study. Circulation 1995;92:2935-9.

13. Beder SD, Kuehl KS, Hopkins RA, Tonder LM, Mans DR. Precipitous exit block with epicardial steroid-eluting leads. PACE 1997;20:2954-7.

14. Cutler NG, Karpawich PP, Cavitt D, Hakimi M, Walters HL. Steroid-eluting epicardial pacing electrodes: six year experience of pacing thresholds in a growing pediatric population. PACE 1997;20:2943-8

15. Figa FH, McCrindle BW, Bigras JL, Hamilton RM, Gow RM. Risk factors for venous obstruction in children with transvenous pacing leads. PACE 1997;20:1902-9.

16. Ward DE, Jones S, Shinebourne EA. Long-term transvenous pacing in children weighing ten kilograms or less. Int J Cardiol 1987; 15:112-5.

17. Till JA, Jones S, Rowland E, Shinebourne EA, Ward DE. Endocardial pacing in infants and children $15 \mathrm{~kg}$ or less in weight: medium-term follow-up. PACE 1990;13:1385-92.

18. Friedman RA, Van Zandt H, Collins E, LeGras M, Perry J. Lead extraction in young patients with and without congenital heart disease using the subclavian approach. PACE 1996;19: 778-83.

19. Byrd CL, Schwartz SJ, Hedin N. Intravascular techniques for extraction of permanent pacemaker leads. J Thorac Cardiovasc Surg 1991;101:989-97.

\section{Online-www.aats.org}

Now you can get The Journal of Thoracic and Cardiovascular Surgery online. The Journal online brings you faster delivery time, easy searching of current and back issues, links to PubMed, AATS, WTSA and other important sites, and more. Visit the Journal online today. 